\title{
Roll-your-own tobacco use among Canadian youth: current prevalence and changes in youth smoking "rollies" since 2008
}

\author{
A. G. Cole, MSc (1); S. T. Leatherdale, PhD (1); V. L. Rynard, MSc (2)
}

This article has been peer reviewed.

Tweet this article

\begin{abstract}
Introduction: Roll-your-own (RYO) cigarettes, or "rollies," represent an affordable alternative to manufactured cigarettes, especially among youth with a lower disposable income. This study characterizes changes in the prevalence of RYO tobacco current use between 2008 and 2010 in Canadian youth and examines the sociodemographic characteristics associated with RYO use in 2010.
\end{abstract}

Methods: This study uses representative data collected from grade 9 to 12 students as part of the 2008/2009 and 2010/2011 cycles of the Canadian Youth Smoking Survey (YSS).

Results: Among current smokers, 30.5\% currently use RYO cigarettes. Youth with a disposable income of more than $\$ 100$ each week were less likely to be current RYO users $(\mathrm{OR}=0.49,95 \% \mathrm{CI}: 0.34-0.71)$. Current RYO tobacco users were more likely to be current alcohol users (OR $=2.01,95 \% \mathrm{CI}: 1.09-3.72)$ or marijuana users $(\mathrm{OR}=2.63$, 95\% CI: $1.73-4.01)$.

Conclusion: RYO cigarettes continue to provide an affordable alternative to youth smokers. Targeted school-based prevention programs that address the use of RYO cigarettes may offer additional reductions to the use of RYO cigarettes.

Keywords: roll-your-own tobacco, adolescent, smoking, alcohol use, marijuana smoking

\section{Introduction}

Despite substantial declines in the sale of manufactured cigarettes in recent years, the sale of more affordable tobacco products, such as roll-your-own (RYO) tobacco, has increased across the population. ${ }^{1}$ Research suggests that most current smokers use RYO cigarettes ("rollies") because they are less expensive. ${ }^{2-4}$ This substitution poses significant barriers to current public health policies that attempt to discourage smoking through taxation, especially since loose tobacco for RYO cigarettes tends to be cheaper than manufactured cigarettes. ${ }^{5}$ It is important to understand how prevalent RYO tobacco use is among youth as they are the most price-sensitive population of smokers. ${ }^{6}$

RYO tobacco is characterized as a handrolled cigarette using loose tobacco and cigarette papers that may or may not be smoked with a filter. ${ }^{7}$ Evidence suggests that RYO cigarettes are at least as harmful as manufactured cigarettes ${ }^{8-9}$ and contribute to the development of many cancers. ${ }^{10-12}$ Data are limited with respect to RYO use in Canada, especially among youth populations. According to the 2002 Canadian Tobacco Use Monitoring Survey, $17 \%$ of current adult smokers over the age of 15 years reported smoking RYO cigarettes, ${ }^{13}$ while data from the
2008/2009 Youth Smoking Survey suggest that current RYO cigarette use is more prevalent among youth populations $(24 \%) .^{14}$

Because most studies have concentrated on RYO tobacco use among adult smokers, there is little evidence for predictors of use among youth. A common finding is that adult smokers who use RYO cigarettes are more likely to have a lower income $e^{7,13,15,16}$ and are more likely to be heavier smokers. ${ }^{4,13,15}$ RYO users are also less likely to consider or to have made a recent quit attempt compared to manufactured cigarette users. ${ }^{4,13,16}$ Additional sociodemographic factors associated with RYO cigarette use in adult smokers include younger age, male sex, and having many friends who smoke. ${ }^{4,7,16,17}$

As with the findings for adult smokers, the population of youth RYO users is more likely to be younger and male $\mathrm{e}^{14,17}$ and more likely to have less disposable income. ${ }^{14}$ Compared to adult RYO users who favour one tobacco product over the other, youth and young adult users are also more likely to use both cigarettes and RYO tobacco. ${ }^{7,16}$ Youth who use RYO cigarettes are also more likely to use marijuana regularly. ${ }^{14}$ International data suggest that not only is RYO tobacco use in youth on the rise, ${ }^{17}$ but it is also higher in youth than in any other age group. ${ }^{7}$ Therefore, we need to further evaluate changes in the prevalence of RYO tobacco use among Canadian youth to help inform future tobacco control policies.

The purpose of this study is to characterize changes in the prevalence of RYO 
tobacco use between 2008 and 2010 among Canadian youth and to examine the sociodemographic characteristics that are associated with current use with the most recent wave of nationally representative data of Canadian youth smokers in grades 9 to 12 .

\section{Methods}

This study used representative data collected as part of the 2008/2009 and 2010/ 2011 cycles of the Canadian Youth Smoking Survey (YSS). Detailed information on the sample design, methods and survey rates for the 2008/2009 YSS have been described elsewhere ${ }^{18}$ and are also available online (www.yss.uwaterloo.ca). The 2010/2011 YSS collected data from 31396 Canadian students in grades 9 to 12 . The target population for the data consisted of all young Canadian residents in grades 9 to 12 attending public, private and Catholic secondary schools in 9 Canadian provinces. While New Brunswick had participated in the previous cycles of YSS, they did not participate in $2010 / 2011$, so youth in that province were excluded from the target populations in 2010 and their student responses were removed from the 2008 data set before analysis. Youth in Yukon, Nunavut and the Northwest Territories as well as in institutions, special schools or schools on military bases or on First Nation Reserves were also excluded. The YSS was administered to students during class time and participants were not compensated. The survey design and sample weight allow for the production of populationbased estimates within this manuscript.

A combination of active informationpassive permission and active permission protocols were used to recruit students in the 2010/2011 YSS. Students also had the opportunity to decline participation on the day of data collection. The University of Waterloo Office of Research Ethics and appropriate School Board and Public Health Ethics committees approved all procedures, including passive consent.

To be consistent with Health Canada's definitions of smoking status for the YSS, ${ }^{18}$ we defined current daily smokers as having smoked at least 100 cigarettes in their lifetime and at least one whole
TABLE 1

Weighted descriptive statistics for roll-your-own tobacco current use for the sample of current smokers (grades 9-12), 2010/2011 Youth Smoking Survey, Canada

\begin{tabular}{|c|c|c|}
\hline \multirow[t]{2}{*}{ Parameters } & $\begin{array}{l}\text { Roll-Your-Own Tobacco } \\
\text { Current Use }(\mathrm{N}=41900)^{\mathrm{a}}\end{array}$ & \multirow[t]{2}{*}{ Chi-square } \\
\hline & $\%$ of students & \\
\hline \multicolumn{3}{|l|}{ Sex } \\
\hline Female & 38.6 & $\chi^{2}=9.4 ; p<.01 ; d f=1$ \\
\hline Male & 61.4 & \\
\hline \multicolumn{3}{|l|}{ Grade } \\
\hline 9 & 18.0 & $\chi^{2}=84.2 ; p<.001 ; d f=3$ \\
\hline 10 & 29.0 & \\
\hline 11 & 27.6 & \\
\hline 12 & 25.5 & \\
\hline \multicolumn{3}{|l|}{ Region } \\
\hline Atlantic ${ }^{b}$ & 11.2 & $\chi^{2}=84.9 ; p<.001 ; d f=4$ \\
\hline Quebec & $18.4^{\mathrm{E}}$ & \\
\hline Ontario & 23.7 & \\
\hline Prairies $^{c}$ & 23.8 & \\
\hline British Columbia & 23.0 & \\
\hline \multicolumn{3}{|l|}{ Ethnicity } \\
\hline White & 65.6 & $\chi^{2}=33.8 ; p<.001 ; d f=3$ \\
\hline Black, Latin, Other & 18.3 & \\
\hline Asian & 3.7 & \\
\hline Aboriginal & 12.4 & \\
\hline \multicolumn{3}{|l|}{ Smoking classification } \\
\hline Daily smoker ${ }^{\mathrm{d}}$ & 62.4 & $\chi^{2}=112.8 ; p<.001 ; d f=1$ \\
\hline Occasional smoker ${ }^{\mathrm{e}}$ & 37.6 & \\
\hline
\end{tabular}

Number of cigarettes usually smoked each day over the last 30 days, $\mathbf{n}$

$\begin{array}{lll}\leq 5 & 37.1 & \chi^{2}=155.6 ; p<.001 ; d f=2 \\ 6-10 & 28.0 & \\ \geq 11 & 34.9\end{array}$

Attempts to quit smoking cigarettes, $\mathrm{n}$

$0 \quad 37.3 \quad \chi^{2}=19.5 ; p<.001 ; d f=2$

$1 \quad 20.8$

$\geq 2 \quad 41.9$

Reasons why respondents smoke the reported brand of cigarettes ${ }^{f}$

$\begin{array}{lrr}\text { My friends smoke the same brand } & 14.6 & \chi^{2}=6.6 ; p<.05 ; d f=1 \\ \text { This brand costs less than other brands } & 23.1 & \chi^{2}=0.2 ; p>.05 ; d f=1 \\ \text { I like the image of this brand } & 6.3 & \chi^{2}=14.7 ; p<.001 ; d f=1 \\ \text { I like the taste } & 67.2 & \chi^{2}=8.0 ; p<.01 ; d f=1\end{array}$

Ever used blunt wraps

Yes $\quad 46.7 \quad \chi^{2}=157.2 ; p<.001 ; d f=1$

No $\quad 53.3$

Used blunt wraps in the last 30 days

Yes $\quad 30.7 \quad \chi^{2}=181.6 ; p<.001 ; d f=1$

No $\quad 69.3$

Continued on the following page 
TABLE 1 (continued)

Weighted descriptive statistics for roll-your-own tobacco current use for the sample of current smokers (grades 9-12), 2010/2011 Youth Smoking Survey, Canada

\begin{tabular}{|c|c|c|}
\hline \multirow[t]{2}{*}{ Parameters } & $\begin{array}{l}\text { Roll-Your-Own Tobacco } \\
\text { Current Use }(\mathrm{N}=41900)^{\mathrm{a}}\end{array}$ & \multirow[t]{2}{*}{ Chi-square } \\
\hline & $\%$ of students & \\
\hline \multicolumn{3}{|c|}{ Number of close friends that smoke cigarettes, $n$} \\
\hline 0 & $3.0^{\mathrm{E}}$ & $\chi^{2}=133.5 ; p<.001 ; d f=5$ \\
\hline 1 & $2.2^{\mathrm{E}}$ & \\
\hline 2 & 6.0 & \\
\hline 3 & 6.4 & \\
\hline 4 & 4.3 & \\
\hline$\geq 5$ & 78.6 & \\
\hline \multicolumn{3}{|c|}{ Amount of money respondents usually get each week to spend on themselves or to save, $\$$} \\
\hline 0 & 11.2 & $\chi^{2}=4.0 ; p>.05 ; d f=4$ \\
\hline $1-20$ & 26.2 & \\
\hline 21-100 & 29.0 & \\
\hline$>100$ & 24.4 & \\
\hline I do not know & 9.1 & \\
\hline \multicolumn{3}{|c|}{ Alcohol use in the last 12 months } \\
\hline Non-user ${ }^{g}$ & 4.1 & $\chi^{2}=31.1 ; p<.001 ; d f=2$ \\
\hline Occasional $^{\mathrm{h}}$ & 44.8 & \\
\hline Current $^{i}$ & 51.1 & \\
\hline \multicolumn{3}{|c|}{ Marijuana use in the last 12 months } \\
\hline Non-user ${ }^{g}$ & 5.7 & $\chi^{2}=91.7 ; p<.001 ; d f=2$ \\
\hline Occasional $^{\mathrm{h}}$ & 22.1 & \\
\hline Current ${ }^{i}$ & 72.2 & \\
\hline
\end{tabular}

${ }^{\text {a }}$ Weighted sample estimate, as described in the methods.

b Atlantic region includes Newfoundland and Labrador, Prince Edward Island and Nova Scotia (as described in the methods, New Brunswick was not part of the 2010/2011 YSS sample).

c Prairie region includes Manitoba, Saskatchewan and Alberta.

${ }^{d}$ Daily smokers smoked at least 100 cigarettes in their lifetime and at least 1 whole cigarette on each of 30 days preceding the survey.

e Current occasional smokers had smoked at least 100 cigarettes in their lifetime and at least 1 whole cigarette during the 30 days preceding the survey but not every day.

${ }^{f}$ Respondents were able to select more than one answer.

${ }^{g}$ Non-users did not report use in the previous year.

h Occasional users reported monthly use.

i Current users reported weekly use.

E Moderate sampling variability; interpret with caution.

cigarette on each of 30 days preceding the survey; current occasional smokers had smoked at least 100 cigarettes in their lifetime and at least one whole cigarette during the 30 days preceding the survey but not every day. Among current smokers, we measured RYO tobacco use using one multi-item question on alternate tobacco use: "In the last 30 days, did you use any of the following? (Mark all that apply)." For this analysis, any respondents with all items missing had RYO tobacco current use set to missing.
The YSS also collected information on demographics, weekly spending money, and alcohol and marijuana use. One question measured a respondent's disposable income: "About how much money do you usually get each week to spend on yourself or to save? (Remember to include all money from allowances and jobs like delivering papers...)." As with previous definitions, ${ }^{19,20}$ non-drinkers did not report alcohol use in the last year, occasional drinkers reported monthly alcohol use and current drinkers reported weekly alcohol use. Similarly, non-marijuana users did not report marijuana use in the last year, occasional marijuana users reported monthly marijuana use and current marijuana users reported weekly marijuana use.

We used survey weights in the descriptive statistics to adjust for differential response rates across regions or groups. As described previously, ${ }^{18}$ the development of the survey weight was accomplished in two stages. In the first stage, a weight $\left(\mathrm{W}_{1 \mathrm{j}}\right)$ was created to account for the school selection within health region and school strata (either elementary or secondary based on grade enrolment numbers). A second weight $\left(\mathrm{W}_{2 \mathrm{jg}}\right)$ was calculated to adjust for student non-response. The weights were then calibrated to the provincial sex and grade distribution so that the total of the survey weights by sex, grade and province would equal the actual enrolments in those groups.

We examined descriptive analyses of the sample characteristics according to year of data collection. Using the 2010 data, we then conducted one logistic regression model to examine factors associated with RYO current use. We used the statistical package SAS version 9.2 for all analyses. $^{21}$

\section{Results}

\section{Descriptive statistics for RYO current use}

Among youth in grades 9 to $12,30.5 \%$ who currently smoked manufactured cigarettes reported currently using RYO cigarettes, $15.3 \%$ who formerly smoked manufactured cigarettes reported currently using RYO cigarettes, and $1.0 \%$ who never smoked manufactured cigarettes reported currently using RYO cigarettes. Table 1 shows weighted results of the descriptive statistics for RYO current use in 2010 among youth in grades 9 to 12 .

Figure 1 shows the proportion of students who reported currently smoking RYO cigarettes, by grade, compared across cycles of the YSS. In both 2008 and 2010, the prevalence of RYO cigarette current use is greater among grade 12 than grade 9 students. Overall, the prevalence of RYO 
current use decreased between 2008 and 2010 by about $5 \%$, although this change was not significant $\left(\chi^{2}=1.4 ; p>.05 ; d f=1\right)$.

In 2008 and 2010, the use of RYO cigarettes was consistently higher in the Atlantic region and British Columbia and consistently lower in Quebec and Ontario. Between 2008 and 2010, the use of RYO cigarettes decreased in British Columbia and increased in the Atlantic region and Quebec, but remained relatively stable in both Ontario and the Prairie region (see Figure 2).

\section{Logistic regression model results for current use of RYO cigarettes}

Weighted results of the regression model examining current use of RYO cigarettes among current youth smokers are summarized in Table 2. The sex differences between the odds of currently using and not currently using RYO cigarettes were not significant $(\mathrm{OR}=1.09$, $95 \% \mathrm{CI}$ : $0.88-$ 1.36). Students in grade 10,11 and 12 were significantly less likely to be current RYO users compared to students in grade $9(\mathrm{OR}=0.67,95 \% \mathrm{CI}: 0.48-0.95$; $\mathrm{OR}=$ 0.53, $95 \%$ CI: $0.38-0.73$; and $\mathrm{OR}=0.29$, $95 \%$ CI: 0.20-0.42, respectively). Further, current RYO users were less likely to be occasional smokers $(\mathrm{OR}=0.47,95 \% \mathrm{CI}$ : $0.37-0.58)$, to have tried quitting cigarettes once (OR $=0.62$, $95 \%$ CI: $0.47-0.83$ ) or 2 or more times (OR $=0.61,95 \% \mathrm{CI}$ : $0.48-0.78$ ), and to usually have a disposable income between $\$ 21$ and \$100 (OR $=0.61,95 \%$ CI: $0.42-0.87)$ or more than $\$ 100$ each week (OR $=0.49,95 \% \mathrm{CI}$ : 0.34-0.71) compared to those who were not current RYO users. In contrast, current RYO users were more likely to describe themselves as Black, Latin or other (OR = 1.54, $95 \%$ CI: $1.13-2.11$ ), to smoke RYO cigarettes because they like the image of the brand $(\mathrm{OR}=1.82,95 \% \mathrm{CI}$ : $1.11-$ 2.99), to have ever tried using blunt wraps* $(\mathrm{OR}=2.61,95 \% \mathrm{CI}: 2.05-3.31)$, to be occasional (OR $=2.69,95 \% \mathrm{CI}$ : 1.46-4.96) or current drinkers (OR = 2.01, 95\% CI: $1.09-3.72)$ and to be occasional $(\mathrm{OR}=3.09,95 \% \mathrm{CI}: 1.97-4.83)$
FIGURE 1

Proportion of youth currently using roll-your-own tobacco, by grade, 2008/2009 and 2010/2011 Youth Smoking Survey, Canada

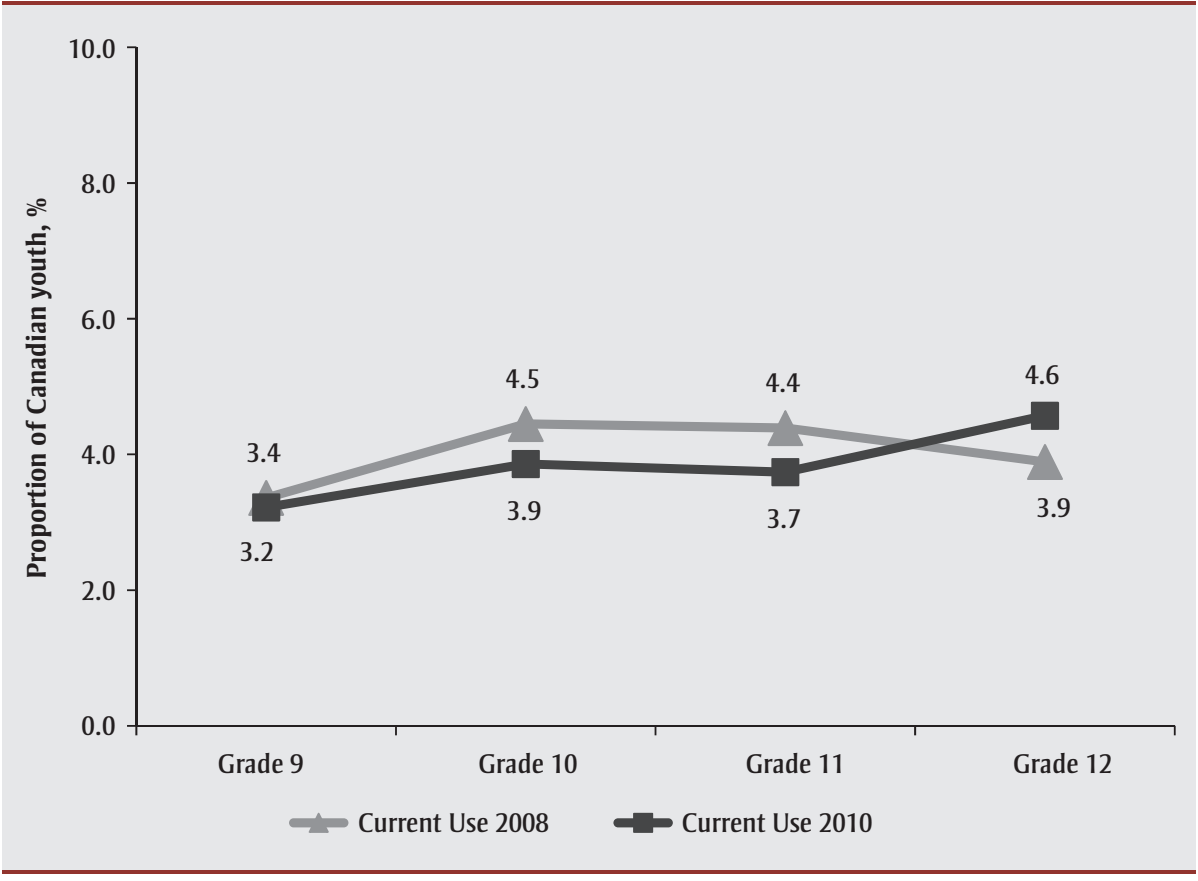

FIGURE 2

Proportion of youth currently using roll-your-own tobacco, by region, 2008/2009 and 2010/2011 Youth Smoking Survey, Canada

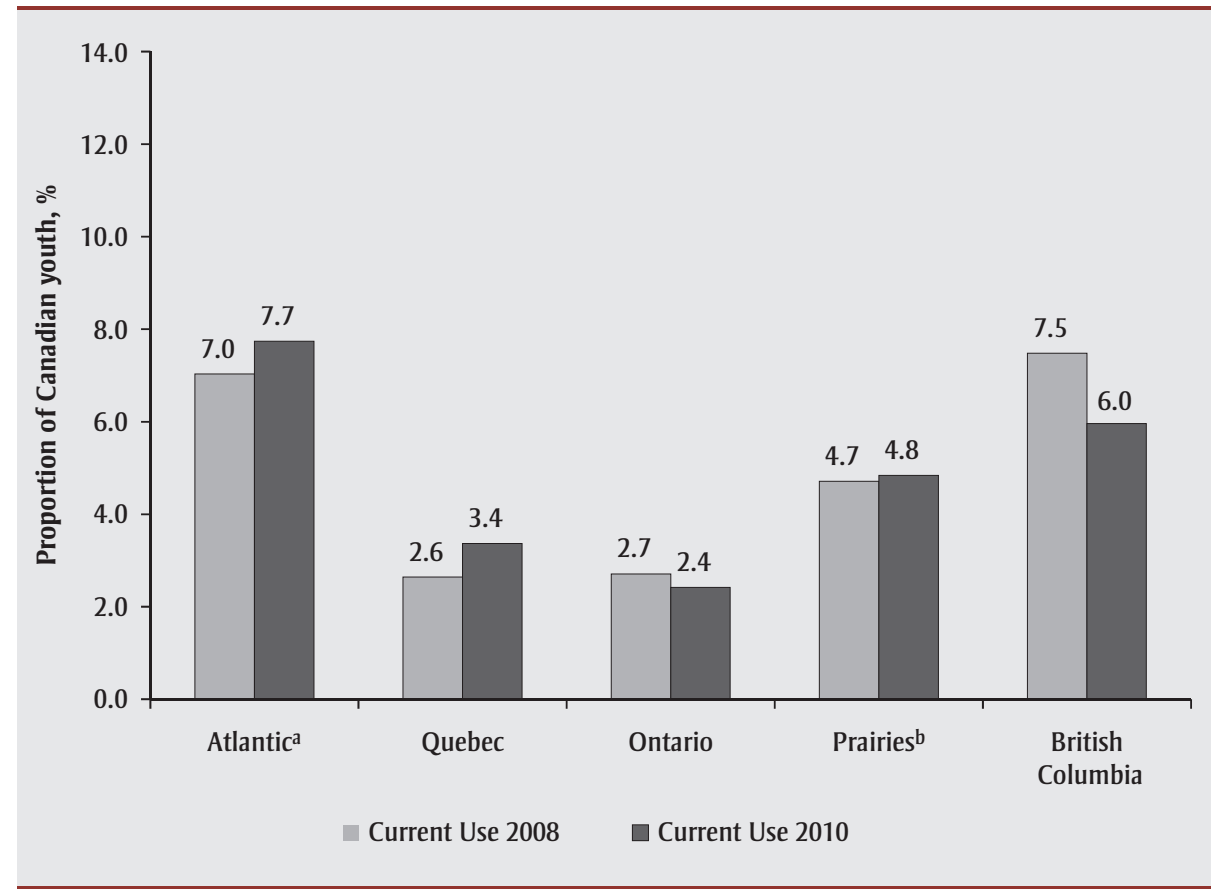

${ }^{a}$ Atlantic region includes Newfoundland and Labrador, Prince Edward Island and Nova Scotia (as described in the methods, New Brunswick was not part of the 2010/2011 YSS sample).

b Prairie region includes Manitoba, Saskatchewan and Alberta.

\footnotetext{
${ }^{*}$ Cigarette rolling papers made of tobacco.
} 
TABLE 2

Logistic regression model examining factors associated with current use of roll-your-own tobacco among current youth smokers (grades 9-12), 2010/2011 Youth Smoking Survey, Canada

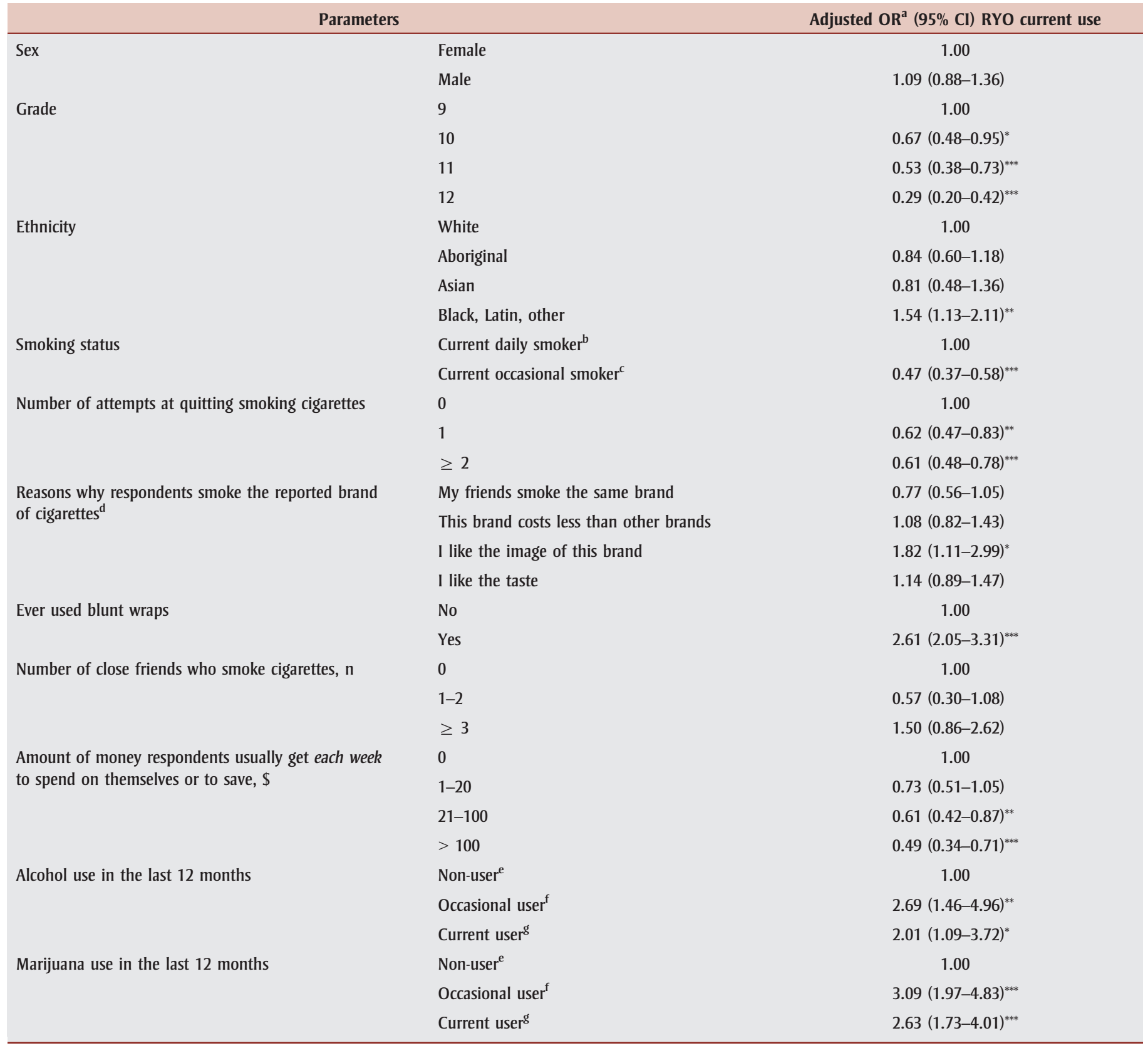

Abbreviations: $\mathrm{Cl}$, confidence interval; OR, odds ratio; RYO, roll-your-own.

${ }^{a}$ Odds ratios controlling for region and adjusted for all other variables in the table; $1=$ Currently uses RYO tobacco ( $n=886$ ), $0=$ Never used RYO tobacco ( $n=1466$ ).

b Daily smokers smoked at least 100 cigarettes in their lifetime and at least one whole cigarette on each of 30 days preceding the survey.

c Current occasional smokers had smoked at least 100 cigarettes in their lifetime and at least one whole cigarette during the 30 days preceding the survey but not every day.

d Reference group includes those who did not respond and those who responded "No."

e Non-users did not report use in the previous year.

${ }^{\mathrm{f}}$ Occasional users reported monthly use.

8 Current users reported weekly use.

${ }^{*} p<.05$.

** $p<.01$.

${ }^{* * *} p<.001$. 
or current marijuana users $(\mathrm{OR}=2.63$, 95\% CI: 1.73-4.01).

\section{Discussion}

Our data indicate that RYO tobacco use, although not as high as the current use rates for manufactured cigarettes, is not a negligible issue in Canada as almost onethird of current youth smokers (representing over 40000 Canadian youth smokers in grades 9 to 12) were current RYO users in 2010. Comparative data between 2008 and 2010 indicate that the prevalence of current RYO cigarette use among Canadian youth has remained relatively stable, potentially mirroring stable rates of manufactured cigarette use. ${ }^{22}$ It is clear that RYO cigarette use among youth is still an important health issue and should continue to be part of tobacco prevention and cessation programs.

Consistent with the literature, our data indicate that youth with a higher disposable income are less likely to be current RYO users. Taxation continues to be an effective method of reducing the prevalence of smoking in youth populations; ${ }^{23}$ however, RYO cigarettes tend to be cheaper than manufactured cigarettes. ${ }^{24}$ In 8 of 10 Canadian provinces, RYO tobacco is taxed at half the rate of manufactured cigarettes, ${ }^{5}$ making RYO cigarettes more affordable. Therefore, we recommend that RYO tobacco taxes increase to reduce the price difference between RYO and manufactured cigarettes. $^{\dagger}$

Our data indicate that youth smokers who use RYO cigarettes are more likely to use marijuana, alcohol and blunt wraps, as does previous research. ${ }^{25}$ Additional research suggests that youth who combine tobacco and marijuana into a blunt are not only more likely to become dependent on both of these substances, but they are also more likely to use other illicit drugs, such as cocaine and hallucinogens. ${ }^{26}$ As a result, school-based prevention programs that address the use of multiple substances continue to be relevant and necessary. ${ }^{27}$ Further, because younger youth were more likely to use RYO cigarettes compared to older youth, programs directed to youth in grades 9 and 10 may be more effective in preventing the use of RYO cigarettes. These programs should target the use of RYO cigarettes specifically, as research indicates that targeted tobacco programs are more effective than general substance abuse programs. ${ }^{28}$ Additional evidence for the effectiveness of such a targeted approach is necessary.

\section{Strengths and limitations}

This study has several strengths. The YSS is a nationally representative survey that occurs every 2 years, providing insight to provincial differences in tobacco use in Canada and allowing researchers to monitor changes in prevalence over time. However, the cross-sectional nature of the data presents some limitations. Causal inferences with respect to variables and RYO current use cannot be made. Further, longitudinal data are required to determine if RYO cigarette current use precedes and leads to marijuana or alcohol use. These data are based on selfreported smoking behaviours; therefore the validity of responses cannot be guaranteed and there may be some bias in the estimates due to student non-response. However, self-report tobacco use measures have previously been demonstrated to be reliable and valid ${ }^{29,30}$ and students were ensured that their responses were confidential.

\section{Conclusions}

Our data indicate that RYO tobacco use is not a negligible issue among Canadian youth. Not only are youth who smoke RYO tobacco more likely to have a lower disposable income, but they are also more likely to use blunt wraps, alcohol and marijuana. More can be done to discourage the use of this product, namely by increasing the tax applied to RYO tobacco to reduce the price disparity between manufactured cigarettes and RYO equiva- lents. Further, targeted school-based prevention programs that address the use of RYO cigarettes may offer additional reductions to the use of RYO cigarettes.

\section{Acknowledgements}

The Youth Smoking Survey is a product of the pan-Canadian capacity building project funded through a contribution agreement between Health Canada and the Propel Centre for Population Health Impact at the University of Waterloo. This pan-Canadian consortium included Canadian tobacco control researchers from all provinces and provided training opportunities for university students at all levels, encouraging their involvement and growth in the field of tobacco control research. Production of this paper has been made possible through a financial contribution from the Ontario Tobacco Research Unit.

\section{References}

1. Connolly GN, Alpert HR. Trends in the use of cigarettes and other tobacco products, 2000-2007. JAMA. 2008;299(22):2629-30.

2. Nosa V, Glover M, Min S, et al. The use of the 'rollie' in New Zealand: preference for loose tobacco among an ethnically diverse low socioeconomic urban population. N Z Med J. 2011;124(1338):25-33.

3. Wilson N, Young D, Weerasekera D, Edwards R, Thomson G, Glover M. The importance of tobacco prices to roll-yourown (RYO) smokers (national survey data): higher tax needed on RYO. N Z Med J. 2009;122(1305):92-6.

4. Young D, Wilson N, Borland R, Edwards R, Weerasekera D. Prevalence, correlates of, and reasons for using roll-your-own tobacco in a high RYO use country: findings from the ITC New Zealand Survey. Nicotine Tob Res. 2010;12(11):1089-98.

5. Ontario Tobacco Research Unit. Tobacco taxes: monitoring update. Monitoring and Evaluation Series (Vol. 16, No. 1). Toronto (ON): Ontario Tobacco Research Unit; 2010. 3 p.

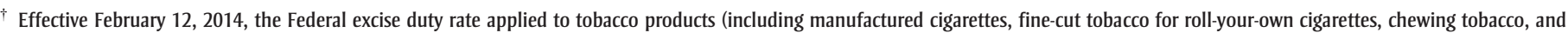
cigars) increased to account for changes in inflation since 2002. Although this marks a positive change in tobacco tax rates, there are still marked differences in the price of roll-your-own and manufactured cigarettes, especially across provinces.
} 
6. Chaloupka FJ, Straif K, Leon ME. Effectiveness of tax and price policies in tobacco control. Tob Control. 2011;20(3): 235-8.

7. Li J, Grigg M, Weerasekera D, et al. Characteristics and quitting success of roll-your-own versus tailor-made cigarette smokers. N Z Med J. 2010;123(1308):64-73.

8. Laugesen $M$, Epton $M$, Frampton $C M$, Glover M, Lea RA. Hand-rolled cigarette smoking patterns compared with factorymade cigarette smoking in New Zealand men. BMC Public Health. 2009;9:194-9. doi: 10.1186/1471-2458-9-194.

9. Shahab L, West R, McNeill A. A comparison of exposure to carcinogens among rollyour-own and factory-made cigarette smokers. Addict Biol. 2009;14(3):315-20. doi: 10.1111/j.1369-1600.2009.00157.x.

10. Tuyns AJ, Esteve J. Pipe, commercial and hand-rolled cigarette smoking in oesophageal cancer. Int J Epidemiol. 1983;12(1):110-3.

11. Engeland A, Haldorsen T, Andersen A, Tretli S. The impact of smoking habits on lung cancer risk: 28 years' observation of 26,000 Norwegian men and women. Cancer Causes Control. 1996;7:366-76.

12. De Stefani E, Oreggia F, Rivero S, Fierro L. Hand-rolled cigarette smoking and risk of cancer of the mouth, pharynx, and larynx. Cancer. 1992;70(3):679-82.

13. Leatherdale ST, Kaiserman M, Ahmed R. The roll-your-own cigarette market in Canada: a cross-sectional exploratory study. Tob Induc Dis. 2009;5(5):1-6. doi: 10.1186/1617-9625-5-5.

14. Leatherdale ST, Burkhalter R. Roll-yourown tobacco use among Canadian youth: is it a bigger problem than we think? BMC Public Health. 2012;12:557. doi: 10.1186 /1471-2458-12-557.

15. Licht AS, Hyland AJ, O'Connor RJ, et al. Socio-economic variation in price minimizing behaviors: findings from the International Tobacco Control (ITC) Four Country Survey. Int J Environ Res Public Health. 2011;8(1): 234-52.
16. Young D, Borland R, Hammond D, et al. Prevalence and attributes of roll-your-own smokers in the International Tobacco Control (ITC) Four Country Survey. Tob Control. 2006;15(Suppl 3):iii76-82.

17. Raisamo SU. Trends in roll-your-own tobacco use among adolescents in Finland, 1981-2009. Prev Med. 2011;53(6):431-2.

18. Elton-Marshall T, Leatherdale ST, Manske SR, Wong K, Ahmed R, Burkhalter R. Research methods of the Youth Smoking Survey (YSS). Chronic Dis Inj Can. 2011;32: 47-54.

19. Leatherdale ST, Burkhalter R. The substance use profile of Canadian youth: exploring the prevalence of alcohol, drug and tobacco use by gender and grade. Addict Behav. 2012;37:318-22.

20. Leatherdale ST, Rynard V. A cross-sectional examination of modifiable risk factors for chronic disease among a nationally representative sample of youth: are Canadian students graduating high school with a failing grade for health? BMC Public Health. 2013;3:569. doi: 10.1186/10.1186 /1471-2458-13-569.

21. SAS Institute Inc. The SAS System for Windows: Version 9.2. Cary (NC): SAS Institute Inc.; 2008.

22. Reid JL, Hammond D, Rynard VL, Burkhalter R. Tobacco use in Canada: patterns and trends, 2014 ed. Waterloo (ON): Propel Centre for Population Health Impact, University of Waterloo; 2014.

23. Carpenter C, Cook PJ. Cigarette taxes and youth smoking: new evidence from national, state and local Youth Risk Behavior Surveys. J Health Econ. 2008;27(2):287-99.

24. Mindell JS, Whynes DK. Cigarette consumption in The Netherlands 1970-1995: does tax policy encourage the use of handrolling tobacco? Eur J Public Health. 2000;10(3):214-9.

25. Crawford GE. Flavoured tobacco products with marijuana names. Tob Contol. 2007; 16:70.

26. Timberlake DS. A comparison of drug use and dependence between blunt smokers and other cannabis users. Subst Use Misuse. 2009;44:401-15.
27. Leatherdale ST, Ahmed R. Alcohol, marijuana, and tobacco use among Canadian youth: do we need more multi-substance prevention programming? J Prim Prev. 2010;31:99-108.

28. Tobler NS, Roona MR, Ochshorn P, Marshall DG, Streke AV, Stackpole KM. School-based adolescent drug prevention programs: 1998 meta-analysis. J Prim Prev. 2000;20(4):275-336.

29. Fendrich M, Mackesy-Amiti ME, Johnson TP, Hubbell A, Wislar JS. Tobacco-reporting validity in an epidemiological drug-use survey. Addict Behav. 2005;30:175-81.

30. Messeri PA, Allen JA, Mowery PD, et al. Do tobacco countermarketing campaigns increase adolescent under-reporting of smoking? Addict Behav. 2007;32:1532-6. 